\title{
Surgical procedures in emphysema: any impact on dynamic hyperinflation?
}

\author{
M.I. Polkey
}

\begin{abstract}
Bullectomy, lung volume reduction surgery and transplantation can palliate dyspnoea in emphysema. The available data suggest that their mode of action, at least with regard to pulmonary mechanics, includes beneficial effects on dynamic hyperinflation. In single lung transplant recipients, this may be asymmetric, causing native lung hyperinflation.
\end{abstract}

KEYWORDS: Bullectomy transplantation, lung volume reduction surgery

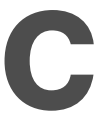
onsiderable data exists to show that, despite maximal medical therapy, advanced emphysema causes disabling breathlessness. Prior to the renaissance of lung volume reduction surgery (LVRS), except for occasional patients who could benefit from a bullectomy [1, 2] or a Monaldi procedure [3], the only surgical therapy available was single lung transplantation (SLT) or double lung transplantation (DLT).

SLT or DLT for emphysema can be effective for the palliation of breathlessness in emphysema, though it probably does not greatly increase lifespan. However, typically the operation has a 1-yr mortality approaching $15 \%$ and donor organs are usually in short supply. Indeed, as there have always been more potential recipients than donors, the technique of lung volume reduction, originally conceived of in 1959 [4], was revived in 1996 by COOPER et al. [5]. The approximate present status of LVRS is that forced expiratory volume in one second (FEV1) is increased in $75 \%$ of patients against a perioperative mortality, which is typically $4-5 \%$ [6-9]. Benefits may be expected to last $\sim 3-5$ yrs in the best responders $[10,11]$ but $\sim 25 \%$ of patients do not derive measurable benefit.

Clearly, the magnitude of benefit varies between LVRS, SLT and DLT. Of course, no study has compared these interventions prospectively and few have directly measured dynamic hyperinflation (DH). Nevertheless, some feel for the benefits of these therapies may be gained from table 1 .

\section{EFFECT OF SPECIFIC THERAPIES ON RESTING AND DH}

\section{Bullectomy}

O'DONNELL et al. [2] followed eight patients who had undergone bullectomy, four of whom also had partial lung resection. Improvement in resting lung volumes was observed (table 1) and DH (i.e. exercise-induced) was also measured using the inspiratory capacity technique, utilising the widely held assumption that total lung capacity does not change. Significant improvements were observed in end-expiratory lung volume (EELV; fig. 1). Relief of exertional breathlessness, measured as change in Borg score during exercise, correlated best with change in EELV.

\section{LVRS}

WISSER et al. [12] reported uncontrolled data on 54 patients undergoing bilateral LVRS. Static lung volumes were reduced by surgery. Dynamic lung volumes were not reported but, interestingly, a significant fall in intrinsic positive end-expiratory oesophageal pressure (PEEPi) was observed, suggesting reduced flow limitation and intuitively less DH. This observation was also reported by TSCHERNKO et al. [13] at rest and during exercise. However, both these studies used the Bicore device, which does not monitor gastric pressure trace, thereby making it difficult to determine how much of the observed PEEP is due to PEEPi and how much is due to abdominal muscle recruitment (for further discussion on this point see [14, 15]). SHADE et al. [16] presented uncontrolled data on 33 patients undergoing bilateral LVRS; although an increase in exercise endurance was observed, dynamic lung volumes were not reported. Similar data were reported by STAMMBERGER et al. [17] and LEYENSON et al. [18].

In the National Emphysema Treatment Trial, significant improvements in walking distance were more likely in patients randomised to the surgical arm, but no data is provided on operating lung volumes during exercise or indeed on static lung volumes [7].

To the best of the present author's knowledge, only one study has sought to measure $\mathrm{DH}$ directly in patients undergoing LVRS [19].
CORRESPONDENCE

M.I. Polkey

Respiratory Muscle Laboratory

Royal Brompton Hospital and

National Heart \& Lung Institute

Fulham Road

London SW3 6NP

UK

Fax: 442073518939

E-mail: m.polkey@

rbh.nthames.nhs.uk 
TABLE 1 Representative data for different surgical therapies in emphysema

\begin{tabular}{|c|c|c|c|c|c|c|c|c|c|}
\hline \multirow[t]{2}{*}{ Surgical intervention } & \multicolumn{2}{|c|}{ FEV1 L } & \multicolumn{2}{|c|}{ TLC L } & \multicolumn{2}{|c|}{ RV L } & \multicolumn{2}{|c|}{ RV:TLC } & \multirow[t]{2}{*}{ [Ref.] } \\
\hline & Pre-op. & Post-op. ${ }^{\#}$ & Pre-op. & Post-op. ${ }^{\#}$ & Pre-op. & Post-op. ${ }^{\#}$ & Pre-op. & Post-op. ${ }^{\#}$ & \\
\hline Bullectomy & 1.13 & 1.44 & 8.02 & 6.91 & 5.28 & 3.73 & & & [2] \\
\hline Bilateral LVRS & 0.77 & 1.10 & 7.58 & 6.32 & 5.33 & 3.65 & & & [12] \\
\hline Bilateral LVRS & 0.73 & 0.92 & 7.3 & 6.3 & 4.8 & 3.4 & 0.65 & 0.54 & [13] \\
\hline
\end{tabular}

Data presented as mean, unless otherwise stated. FEV1: forced expiratory volume in one second; TLC: total lung capacity; RV: residual volume; Pre-op.: pre-operative Post-op.: post-operative; LVRS: lung volume reduction surgery. ${ }^{*}$ : post-op. values chosen from as close as possible to 3 months.

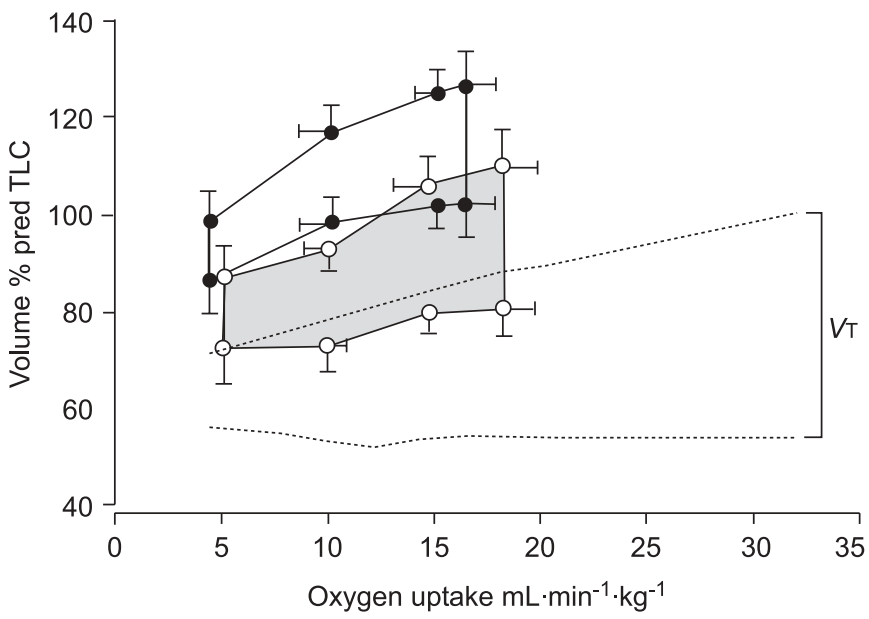

FIGURE 1. Dynamic lung volumes before $(\bullet)$ and after $(\bigcirc)$ bullectomy in eight subjects during an incremental exercise test. Area marked by dotted lines indicates the predicated values for normal subjects. \% pred: \% predicted; TLC: total lung capacity; VT: tidal volume. Reproduced and modified from [2] with permission from the publisher.

MARTINEZ et al. [19] studied 17 patients before and after bilateral LVRS; DH was measured in a subgroup of 12 using the inspiratory capacity technique. A reduction in both EELV and end-inspiratory lung volume was observed after surgery, typically by $\sim 1 \mathrm{~L}$. As shown in figure 2 , relief of breathlessness was strongly associated with reduced DH. Reduction in DH was not clearly related to improvement in FEV1, mirroring subsequent observations from pharmacological studies [20].

\section{Lung transplantation}

MARTINEZ et al. [21] also studied SLT and DLT recipients using the inspiratory capacity technique. Clearly it was not possible to obtain data from patients prior to surgery but those authors found that most DLT patients could reach their peak exercise without increasing EELV; mean EELV at peak exercise was $100 \mathrm{~mL}$ less than resting. In contrast, eight out of eight SLT recipients increased EELV during exercise by a mean of $370 \mathrm{~mL}$ (fig. 3). This observation was repeated in SLT recipients by MURCIANO et al. [22]. If it is clear that SLT patients usually develop DH whilst DLT patients frequently do not, it seems likely that SLT patients could develop native lung hyperinflation during exercise (and conversely that the transplanted lung
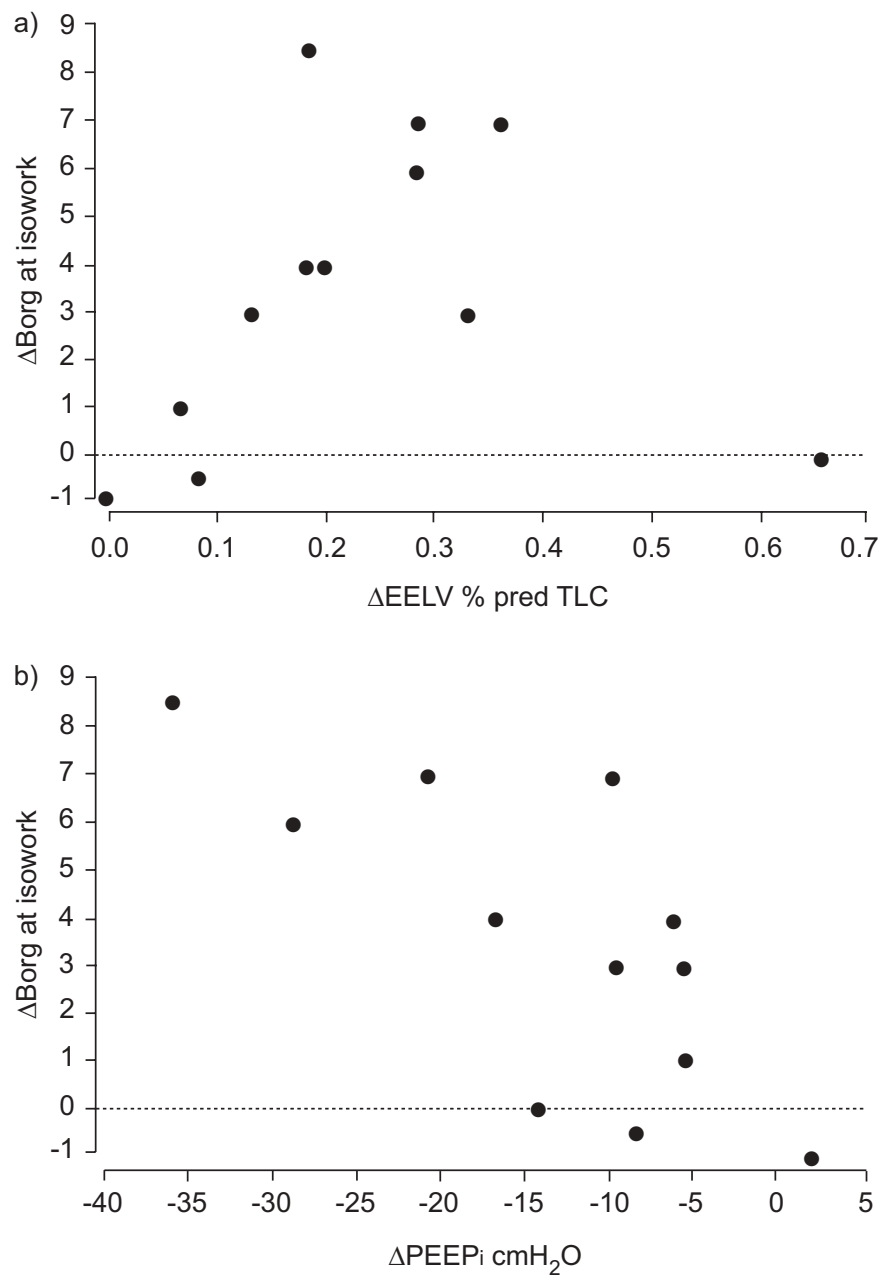

FIGURE 2. The change in Borg score at isowork in 12 patients during an incremental exercise protocol is shown on the vertical axis. Reduced breathlessness is strongly related to a) reduced dynamic hyperinflation and to its indirect relation, b) reduced intrinsic positive end-expiratory pressure (PEEPi). $\triangle E E L V$ : change in end-expiratory lung volume; \% pred: \% predicted; TLC: total lung capacity. Reproduced from [19] with permission from the publisher.

does not). This has not, to the best of the present author's knowledge, been identified during exercise but it has been identified at rest, and LVRS to the native lung may be of benefit in this situation [23]. 


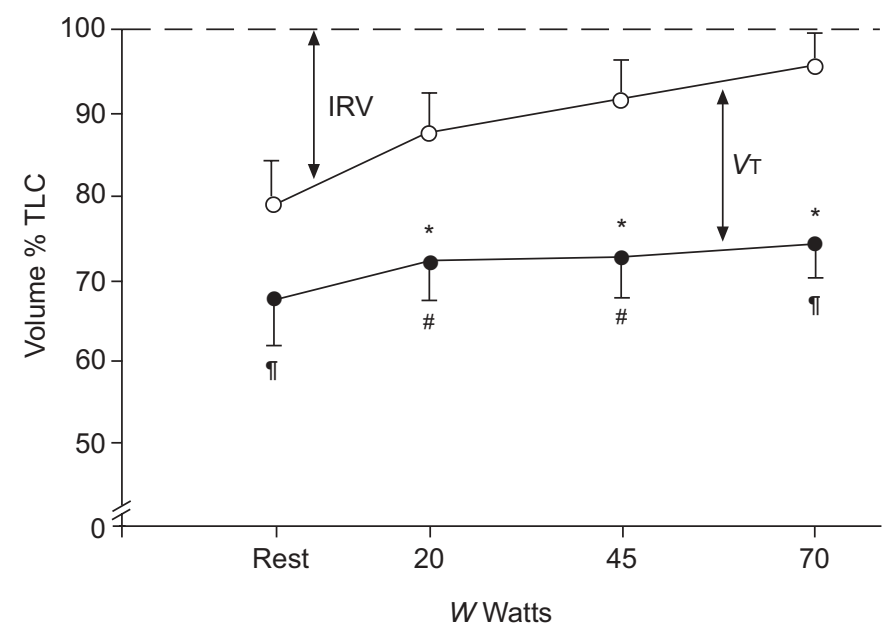

FIGURE 3. Progression of operating lung volumes during incremental exercise in emphysema patients who have undergone single lung transplantation. $\bigcirc$ : endinspiratory lung volume; $\bullet$ : end-expiratory lung volume. IRV: inspiratory reserve volume; VT: tidal volume; TLC: total lung capacity; W: external power. ${ }^{*}: n=8 ;{ }^{*}: n=7$. *: $p<0.05$. Reproduced and modified from [22] with permission from the publisher

\section{CONCLUSION}

Although physiological data are sparser than desired, various surgical interventions can palliate dyspnoea and probably do so in part by reducing hyperinflation. Understanding the mechanisms underlying dynamic hyperinflation, particularly with regard to collateral ventilation, may allow better selection of patients for surgery.

\section{REFERENCES}

1 Soni R, McKeough ZJ, Dobbin CJ, Young IH. Gas exchange and exercise tolerance following bullectomy. Respirology 2005; 10: 120-123.

2 O'Donnell DE, Webb KA, Bertley JC, Chau LK, Conlan AA. Mechanisms of relief of exertional breathlessness following unilateral bullectomy and lung volume reduction surgery in emphysema. Chest 1996; 110: 18-27.

3 Venn GE, Williams PR, Goldstraw P. Intracavity drainage for bullous, emphysematous lung disease: experience with the Brompton technique. Thorax 1988; 43: 998-1002.

4 Brantigan OC, Mueller E, Kress MB. A surgical approach to pulmonary emphysema. Am Rev Respir Dis 1959; 80: 194-206.

5 Cooper J, Patterson G, Sundaresan R, et al. Results of 150 consecutive bilateral lung volume reduction procedures in patients with severe emphysema. J Thorac Cardiovasc Surg 1996; 112: 1319-1330.

6 Criner GJ, Cordova FC, Furukawa S, et al. Prospective randomized trial comparing bilateral lung volume reduction surgery to pulmonary rehabilitation in severe chronic obstructive pulmonary disease. Am J Respir Crit Care Med 1999; 160: 2018-2027.

7 Fishman A, Martinez F, Naunheim K, et al. A randomized trial comparing lung-volume-reduction surgery with medical therapy for severe emphysema. N Engl J Med 2003; 348: 2059-2073.

8 Geddes D, Davies M, Koyama H, et al. Effect of lungvolume-reduction surgery in patients with severe emphysema. N Engl J Med 2000; 343: 239-245.
9 Miller JD, Berger RL, Malthaner RA, et al. Lung volume reduction surgery $v s$ medical treatment: for patients with advanced emphysema. Chest 2005; 127: 1166-1177.

10 Ciccone AM, Meyers BF, Guthrie TJ, et al. Long-term outcome of bilateral lung volume reduction in 250 consecutive patients with emphysema. J Thorac Cardiovasc Surg 2003; 125: 513-525.

11 Gelb AF, McKenna RJ Jr, Brenner M, Schein MJ, Zamel N, Fischel R. Lung function 4 years after lung volume reduction surgery for emphysema. Chest 1999; 116: 1608-1615.

12 Wisser W, Tschernko E, Wanke T, et al. Functional improvements in ventilatory mechanics after lung volume reduction surgery for homogeneous emphysema. Eur J Cardiothorac Surg 1997; 12: 525-530.

13 Tschernko EM, Gruber EM, Jaksch P, et al. Ventilatory mechanics and gas exchange during exercise before and after lung volume reduction surgery. Am J Respir Crit Care Med 1998; 158: 1424-1431.

14 Kyroussis D, Polkey MI, Keilty SEJ, et al. Exhaustive exercise slows inspiratory muscle relaxation rate in chronic obstructive pulmonary disease. Am J Respir Crit Care Med 1996; 153: 787-793.

15 Purro A, Appendini L, Patessio A, et al. Static intrinsic PEEP in COPD patients during spontaneous breathing. Am J Respir Crit Care Med 1998; 157: 1044-1050.

16 Shade D, Cordova F, Lando Y, et al. Relationship between resting hypercapnia and physiologic parameters before and after lung volume reduction surgery in severe chronic obstructive pulmonary disease. Am J Respir Crit Care Med 1999; 159: 1405-1411.

17 Stammberger U, Bloch KE, Thurnheer R, Bingisser R, Weder W, Russi EW. Exercise performance and gas exchange after bilateral video-assisted thoracoscopic lung volume reduction for severe emphysema. Eur Respir J 1998; 12: 785-792.

18 Leyenson V, Furukawa S, Kuzma AM, Cordova F, Travaline J, Criner GJ. Correlation of changes in quality of life after lung volume reduction surgery with changes in lung function, exercise, and gas exchange. Chest 2000; 118: 728-735.

19 Martinez FJ, de Oca MM, Whyte RI, Stetz J, Gay SE, Celli BR. Lung-volume reduction improves dyspnea, dynamic hyperinflation, and respiratory muscle function. Am J Respir Crit Care Med 1997; 155: 1984-1990.

20 Hadcroft J, Calverley PM. Alternative methods for assessing bronchodilator reversibility in chronic obstructive pulmonary disease. Thorax 2001; 56: 713-720.

21 Martinez FJ, Orens JB, Whyte RI, Graf L, Becker FS, Lynch JP 3rd. Lung mechanics and dyspnea after lung transplantation for chronic airflow obstruction. Am J Respir Crit Care Med 1996; 153: 1536-1543.

22 Murciano D, Ferretti A, Boczkowski J, Sleiman C, Fournier M, Milic-Emili J. Flow limitation and dynamic hyperinflation during exercise in COPD patients after single lung transplantation. Chest 2000; 118: 1248-1254.

23 Moy ML, Loring SH, Ingenito EP, Mentzer SJ, Reilly JJ Jr. Causes of allograft dysfunction after single lung transplantation for emphysema: extrinsic restriction versus intrinsic obstruction. Brigham and Women's Hospital Lung Transplantation Group. J Heart Lung Transplant 1999; 18: 986-993. 